\title{
Experiment and Simulation for Rolling of Diamond-Cu Composites
}

\author{
Yun-Long Wang ${ }^{1} \cdot$ Kai-Kun Wang ${ }^{1} \cdot$ Yu-Wei Wang ${ }^{2} \cdot$ Guang-Chen Li $^{3}$
}

Received: 12 October 2016/Revised: 18 November 2016/Published online: 11 March 2017

(C) The Chinese Society for Metals and Springer-Verlag Berlin Heidelberg 2017

\begin{abstract}
We demonstrate an innovative preparation approach of diamond/Cu composites by powder-in-tube technique and rolling. A small copper tube was loaded with $\mathrm{Ti}$ - and $\mathrm{Cu}$-coated diamond particles, and then the diamond particles were combined with $\mathrm{Cu}$ matrix by composite rolling. The morphology and element distribution of the interface between diamond and $\mathrm{Cu}$ were determined by scanning electron microscopy and energy-dispersive spectrometer. Finite element method (FEM) simulation was used to analyze the rolling process associated with experiment by DEFORM-3D. The final experimental results showed that homogeneous distribution of diamond particles could be observed in the center layer of the composites. According to the contrast experiments, the sample, whose diamond particle size is $0.12-0.15 \mathrm{~mm}$ and thickness of pre-rolling is $1.2 \mathrm{~mm}$, showed relatively complete morphologies and homogeneous distribution. Experimental results indicated a poor efficacy of excessive rolling reduction. The thermal conductivity of the composites is about $453 \mathrm{~W}$ $(\mathrm{m} \mathrm{K})^{-1}$ by theoretical calculation. For FEM simulation, rolling strain and temperature field of the composites were simulated by DEFORM-3D. Simulation results were interpreted, and numerical results verified the reliability of the model. The simulation predicted that the local area of large strain, indicative of the strain along the thickness direction, could be intensified by adding diamond particles.
\end{abstract}

KEY WORDS: Diamond/Cu composites; Powder-in-tube technique (PIT); Rolling; Finite element method (FEM) simulation

Available online at http://link.springer.com/journal/40195.

Kai-Kun Wang

kkwang@mater.ustb.edu.cn

1 School of Materials Science and Engineering, University of Science and Technology Beijing, Beijing 100083, China

2 Department of Engineering, University of Leicester, University Road, Leicester LE1 7RH, UK

3 Tianjin Xiangtong Electronic Company LTD, Tianjin 301800, China

\section{Introduction}

The study on preparation technology of metal matrix composites, such as diamond/Cu, $\mathrm{SiCp} / \mathrm{Cu}$ and diamond/ $\mathrm{Al}$, is a hot spot in the field of material processing in recent years [1-4]. Diamond/Cu composite is prepared for electronic packaging because of its high thermal conductivity and moderate thermal expansion coefficient of (4-6) $\times 10^{-6} \mathrm{~K}^{-1}$ [5-7]. The traditional electronic package materials such as $\mathrm{W} / \mathrm{Cu}, \mathrm{Mo} / \mathrm{Cu}, \mathrm{SiCp} / \mathrm{Al}$ composites are not enough to satisfy the needs of high thermal conductivity with increasingly high electronic heat [8-12]. For the selection of materials, diamond has a high thermal conductivity of $2000 \mathrm{~W}(\mathrm{~m} \mathrm{~K})^{-1}$, and $\mathrm{Cu}$ matrix has excellent performance in respects of forming property and machinability [13-16]. However, the poor wettability 
between copper and diamond is a major issue, which downgrades their performance [17, 18]. To modify the bonding interface, appropriate surface treatment can play an important role in bonding strength, bonding degree and density [19]. As a traditional composite preparation technology, hot pressing is a powder metallurgy process for forming metallurgical bonds under certain pressure and temperature to induce sintering and deformation processes [20-22]. Graphitization of diamond [23, 24], which changes its original structure, could occur at the hot pressing temperature and undermine the performance. Cold forming, such as cold rolling, can avoid this problem under a low temperature. It is also more suitable for industrial production than powder metallurgy process. Composite rolling [25-28] is normally used for two metal plates, and both perform well in forming property and machinability.

Powder-in-tube technique (PIT) is a preparation method for the composites [29]. Unlike traditional techniques, the unique structure of copper-clad diamond is available. PIT has an advantage that it is convenient to combine powder with metal matrix by drawing or rolling and it can be used in large-scale production. Unlike traditional high-temperature techniques, graphitization can be avoided at low temperature via PIT and cold rolling.

In this paper, $\mathrm{Ti}$ - and $\mathrm{Cu}$-coated diamond particles involving different particle sizes and mixed or unmixed copper particles were selected. A small copper tube was filled with diamond particles and sealed by pliers. By means of composite rolling, diamond/ $\mathrm{Cu}$ composite board was fabricated and the diamond particles were totally encapsulated in copper and distributed in the middle. Thus, the composites could be potentially used in micro-forming, bend forming, welding, electroplating and other processing such as electronic packaging materials [30-33]. Finally, scanning electron microscope (SEM) and energy-dispersive spectrometer (EDS) were applied to analyze the composition distribution. FEM simulation was applied to predict the area of larger strain.

\section{Experimental}

\subsection{Rolling Experiment}

Five types of particles (number $\mathrm{A}-\mathrm{E}$ ), $\mathrm{Ti}$ (trace, be converted to $\mathrm{TiC}$ by vacuum vapor deposition and diffusion, improving the interfacial bonding [34]) and $\mathrm{Cu}$-coated MBD10 diamond particles are shown as follows:

A. Particle size: $0.09-0.11 \mathrm{~mm}$, diamond/ $\mathrm{Cu}$ mass ratio: $1: 1$;

B. Particle size: $0.12-0.15 \mathrm{~mm}$, diamond/ $\mathrm{Cu}$ mass ratio: $1: 1$
C. Particle size: $0.18-0.21 \mathrm{~mm}$, diamond/Cu mass ratio: $1: 1$

D. Mixed copper powder, diamond volume fraction: $65 \%$, diamond/ $\mathrm{Cu}$ mass ratio: 0.73:1;

E. Mixed copper powder, diamond volume fraction: $75 \%$, diamond/Cu mass ratio: 1.19:1.

Small copper tubes (outer diameter: $2.8 \mathrm{~mm}$, inner diameter: $1.2 \mathrm{~mm}$, thickness: $0.8 \mathrm{~mm}$, length: $50 \mathrm{~mm}$ ).

Parameters of rolling machine: roll radius: $135 \mathrm{~mm}$; roll body length: $200 \mathrm{~mm}$; roll rotating speed: $11 \mathrm{rpm}$.

The small copper tubes were loaded with different types of particles, and then both sides were sealed. There are a total of seven groups, which involve five types of diamond particles and different pre-rolling thicknesses of the rolled sheet with $0.8,1.0$ and $1.2 \mathrm{~mm}$. Multi-pass rolling was used in the experiment, and it is convenient for forming. Figure 1 shows the schematic diagram of the rolling experiment. More attention should be paid on rolling experiment since the copper tubes were small and had high hardness with the diamond particles. Rolling passes and reduction should be under control. Since the rolling reduction device was manually controlled, a small deviation in thickness may occur. The selection of harder steel roll could avoid deformation of the roll due to high stress on the working position. At the same time, a one-time parallel access to the roll gap could avoid the occurrence of skewing.

After annealing for $1 \mathrm{~h}$ at $300{ }^{\circ} \mathrm{C}$ and then air-cooling to the room temperature, the samples were cut from the middle of the composite sheet after rolling. Due to the thin composite sheet, seven types of the samples were glued together for observing. One should be aligned in the horizontal direction (cross section perpendicular to the rolling direction) and the other in vertical direction (longitudinal section).

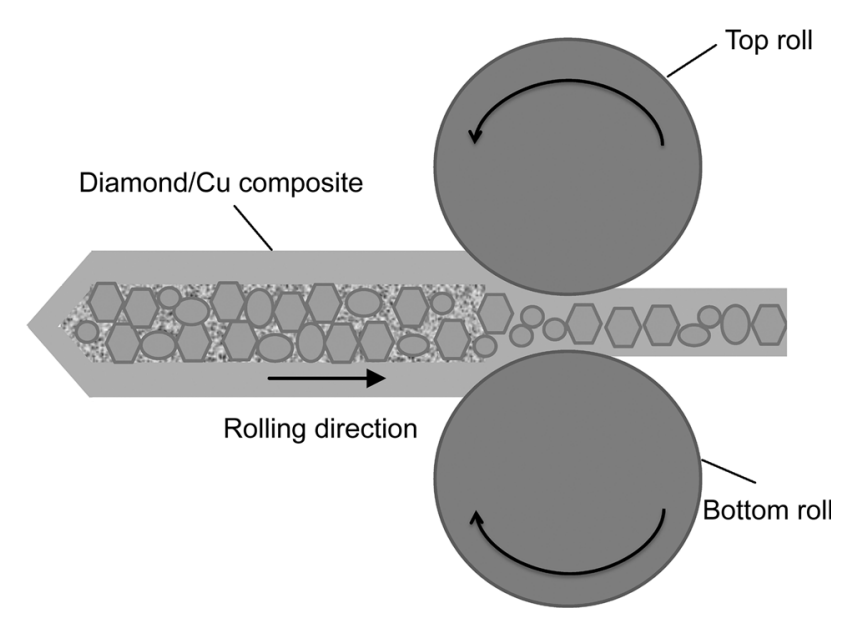

Fig. 1 Schematic diagram of the rolling experiment 
Finally, two groups of the combination could be obtained. The morphology of the samples and element distribution of the interface between diamond and $\mathrm{Cu}$ matrix were observed using a field emission gun SEM, equipped with an energy-dispersive spectroscopy (EDS).

Mass of the sample was measured by analytical balance, and the volume was measured by the method of drainage. Relative density was measured by Archimedes method with self-made instrument and differed from theoretical density because of the interspace of the particles. Table 1 shows the density of the composites measured and the comparison with theoretical value. The influences of rolling reduction and diamond type on the composites were analyzed by groups of No. 1-No. 5 and groups of No. 2, No. 6, No. 7, respectively.

\subsection{FEM Simulation}

Rolling experiments of a single copper tube and diamond/ $\mathrm{Cu}$ composites were simulated by DEFORM-3D. The aim is to analyze rolling strain and temperature field in order to optimize the rolling process [35].

\section{Results and Discussion}

\subsection{Microstructure of Layered Composites}

The layered composites before and after rolling are shown in Fig. 2a, b, respectively. The morphologies of diamond particles and layered composite are shown in Fig. 3.

It could be seen that there was no obvious interspace between the copper layer and diamond layer, indicating a firm bonding between the copper and diamond. Diamond particles were evenly distributed in copper matrix. However, it could be seen that the quantity of the diamond particles was few due to the thick wall of the copper tube. The volume fraction of the diamond particles played an important role in improving the thermal conductivity. As the sole reinforced phase, the quantity of the diamond had

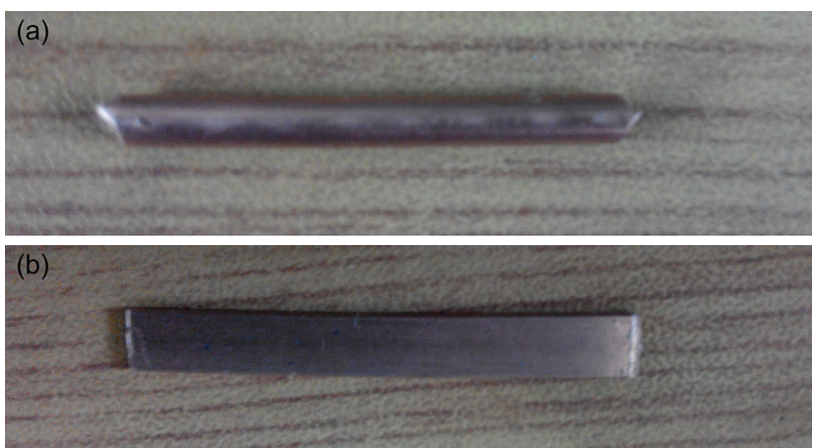

Fig. 2 Photographs of composite samples before $\mathbf{a}$ and after $\mathbf{b}$ rolling

to reach a certain amount to guarantee the strength effect of reinforced phase exceeding that of the interface obstacles. The EDS pattern of the composites is shown in Fig. 4. C and $\mathrm{Cu}$ appeared clearly, and trace Ti could be also found.

The SEM-EDS results are shown in Figs. 5 and 6, indicating a layered distribution of the diamond and copper. The microstructure image was divided into several sections for analysis. From the image, it can be seen that the main components of the composites are copper and diamond. The existence of oxygen element might be from oxidized copper or testing equipment environment, and $\mathrm{Ti}$ was too low to be detected. Due to the vacuum vapor deposition and diffusion, which were carried out in the reaction temperature range of the diamond and $\mathrm{Ti}, \mathrm{TiC}$ may form.

Either in vertical direction or in horizontal direction, the diamond particles were distributed homogeneously and concentrated at the center of the copper layer with no spilling. Obvious contour line could be observed on the interfacial bonding. Most diamond particles showed the integrity, but breakage phenomenon occurred in a certain degree. The assumption could be made that copper on the surface of the diamond was not ground cleanly in consideration of the rough configuration of the diamond. By comparison with all the experimental groups, the composite of No. 7 had relatively complete diamond, larger particles and homogeneous distribution.

Table 1 Density of the composites (samples from No. 1 to No. 7)

\begin{tabular}{lllllll}
\hline Sample & Diamond type & Thickness $(\mathrm{cm})$ & Mass $(\mathrm{g})$ & Volume $\left(\mathrm{cm}^{3}\right)$ & Density $\left(\mathrm{g} \mathrm{cm}^{-3}\right)$ & Theoretical density $\left(\mathrm{g} \mathrm{cm}{ }^{-3}\right)$ \\
\hline No. 1 & A & 1.05 & 1.550 & 0.20 & 7.8 & 8.19 \\
No. 2 & B & 0.90 & 1.562 & 0.20 & 7.8 & 8.19 \\
No. 3 & C & 0.82 & 1.420 & 0.18 & 7.9 & 8.19 \\
No. 4 & D & 1.04 & 1.121 & 0.14 & 8.0 & 8.26 \\
No. 5 & E & 0.99 & 1.131 & 0.14 & 8.1 & 8.16 \\
No. 6 & B & 0.84 & 1.450 & 0.18 & 8.1 & 8.19 \\
No. 7 & B & 1.14 & 1.400 & 0.18 & 7.8 & \\
\hline
\end{tabular}



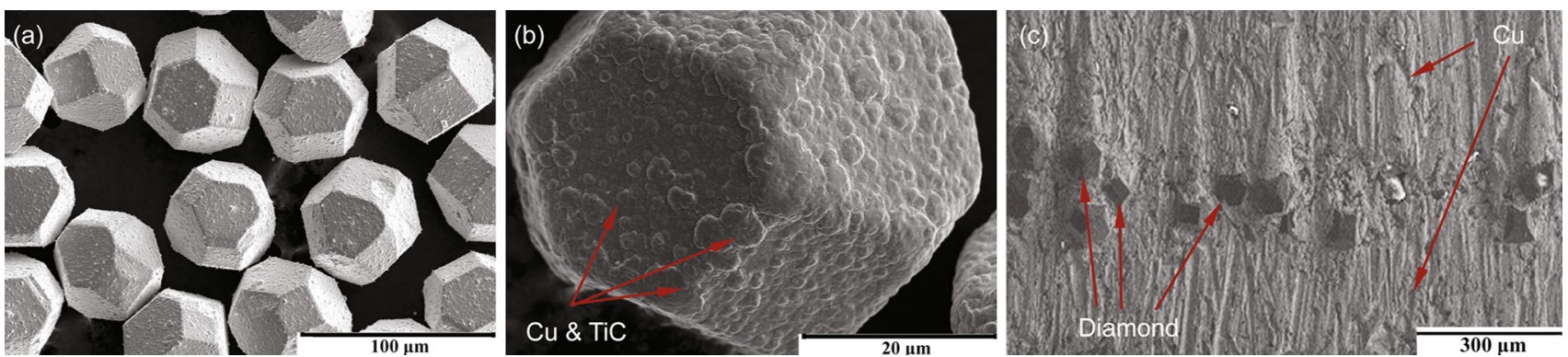

Fig. 3 SEM images of the $\mathrm{Cu}$ - and Ti-coated diamond: different magnifications of the diamond $\mathbf{a}, \mathbf{b}$, layered composite $\mathbf{c}$

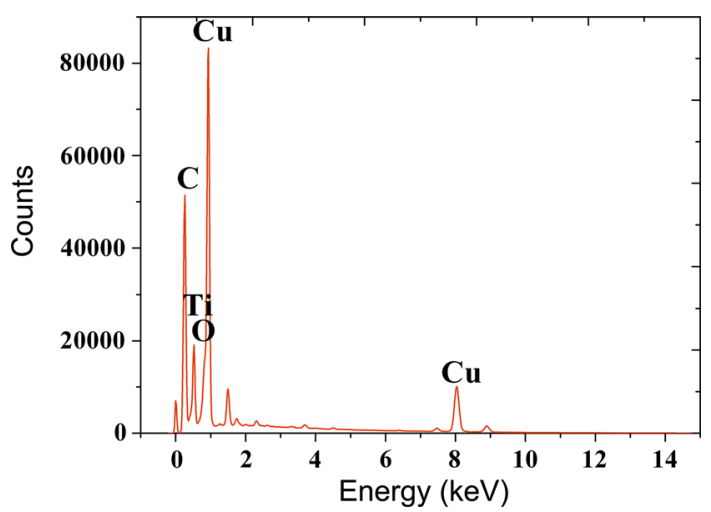

Fig. 4 EDS pattern of the composites

Compared with those in No. 1 and No. 3, the diamond particles in No. 2 had a relatively complete morphology and homogeneous distribution with the particle size of $0.12-0.15 \mathrm{~mm}$. No obvious difference was found in No. 4 and No. 5 with different diamond volume fractions. Compared with those in No. 2 and No. 6, the diamond particles in No. 7 had a relatively complete morphology and homogeneous distribution with the rolled thickness of $1.2 \mathrm{~mm}$. Experimental results showed that a homogeneous distribution was not achieved by increasing rolling reduction. Moderate rolling reduction was one of the key factors for fabricating the diamond/Cu composites with a homogeneous distribution of the diamond particles.

\subsection{Thermal Conductivity Model of Diamond/Cu Composite}

Since the sample size is too small to meet the test requirements for determining thermal performance parameters, thermal conductivity (TC) of the sample is predicted by theoretical calculation. The thermal conductivity model, which is a heat resistance model, is proposed based on the Hasselman and Johnson (H-J) model [36].

$K_{\text {mix }}=\frac{K_{\mathrm{m}}\left[2(\alpha-\beta-1) V_{\mathrm{p}}+(\alpha+2 \beta+2)\right]}{(1-\alpha+\beta) V_{\mathrm{p}}+(\alpha+2 \beta+2)}$
$\alpha=K_{\mathrm{p}} / K_{\mathrm{m}}, \beta=K_{\mathrm{p}} / d h_{\text {mix }}$, where $K$ is the thermal conductivity, $V$ is the volume fraction of inclusions, $d$ is the average diameter of the particles, and the subscripts mix, $m$ and $p$ refer to mixture layer, matrix and reinforcement particles, respectively. $h_{\text {mix }}$ is the intrinsic interfacial thermal conductance, and its reciprocal is the interfacial thermal resistance.

The value of the interfacial thermal conductivity for the composite can be estimated by a simple Debye model in terms of the acoustic mismatch theory $[37,38]$ :

$h_{\text {mix }} \approx 0.5 \rho_{\mathrm{m}} c_{\mathrm{m}} \cdot \frac{v_{\mathrm{m}}^{2}}{v_{\mathrm{p}}^{2}} \cdot \frac{\rho_{\mathrm{m}} \rho_{\mathrm{p}} v_{\mathrm{m}} v_{\mathrm{p}}}{\left(\rho_{\mathrm{m}} v_{\mathrm{m}}+\rho_{\mathrm{p}} v_{\mathrm{p}}\right)^{2}}$,

where $c_{\mathrm{m}}$ is the specific heat of metal, $\rho$ the density, and $v$ the phonon velocity. Subscripts $m$ and $p$ refer to the metal and the reinforcement, respectively. The phonon velocities of the copper and the diamond can be estimated by the equation [39]:

$\frac{1}{v_{1}^{2}}+\frac{2}{v_{\mathrm{t}}^{2}}=\frac{3}{v^{2}}$,

where $v_{1}$ and $v_{\mathrm{t}}$ are the longitudinal and transverse phonon velocities, respectively. The diamond/Cu has longitudinal and transverse phonon velocities equal to $17,500 / 4910$ and $12,800 / 2500$, respectively. $v_{\mathrm{m}}$ and $v_{\mathrm{p}}$ are 2881 and $13,825 \mathrm{~m} / \mathrm{s}$, respectively.

Taking $\rho_{\mathrm{m}}=8920 \mathrm{~kg} / \mathrm{m}^{3}, \quad c_{\mathrm{m}}=385 \mathrm{~J} / \mathrm{kg} \mathrm{K} \quad$ and $\rho_{\mathrm{p}}=3520 \mathrm{~kg} / \mathrm{m}^{3}$ into Eq. (2), we obtain $h_{\text {mix }}=$ $4.78 \times 10^{7} \mathrm{~W} /\left(\mathrm{m}^{2} \mathrm{~K}\right)$. Taking $K_{\mathrm{m}}=400 \mathrm{~W} /(\mathrm{m} \mathrm{K})$, $K_{\mathrm{p}}=2000 \mathrm{~W} /(\mathrm{m} \mathrm{K})$ and $d=120 \mu \mathrm{m}$ into Eq. (1), we obtain $K_{\text {mix }}=995 \mathrm{~W} /(\mathrm{m} \mathrm{K})$. The TC of the whole composite is then considered by the rule of mixture (ROM) as follows:

$K_{\mathrm{c}}=K_{\mathrm{Cu}-\text { outer }} V_{\mathrm{Cu}-\text { outer }}+K_{\text {mix }} V_{\text {mix }}$,

where $K_{\mathrm{c}}$ is the TC of the composite and $K_{\mathrm{Cu} \text {-outer }}$ is the TC of the $\mathrm{Cu}$ outer layers on the top and bottom of the composites. $V_{\text {mix }}=0.225$ and we obtain $K_{\mathrm{c}}=534 \mathrm{~W} /(\mathrm{m} \mathrm{K})$.

However, this model ignores the plating metal Ti. Considering the influence of Ti, Eq. (1) should be modified to: 

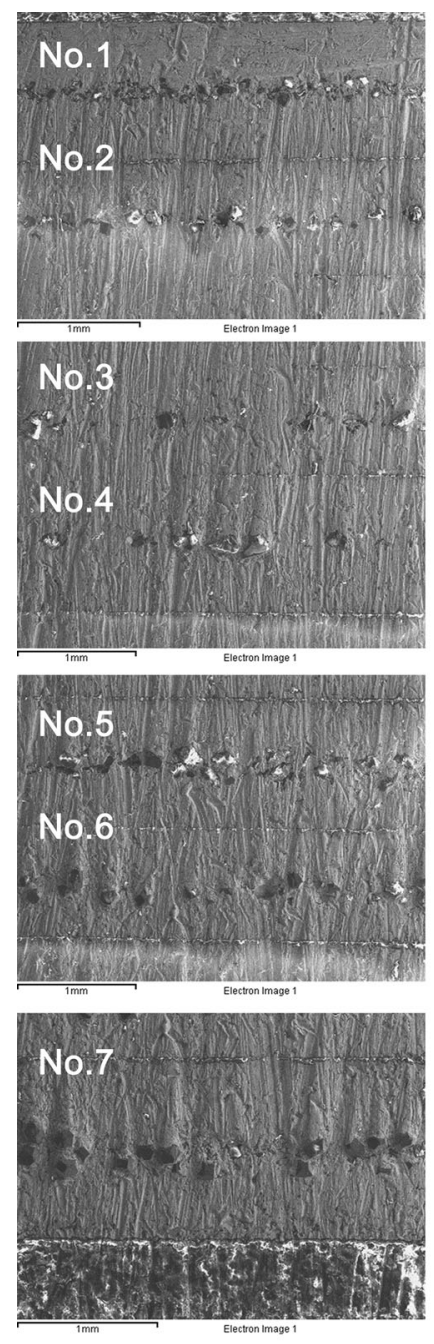
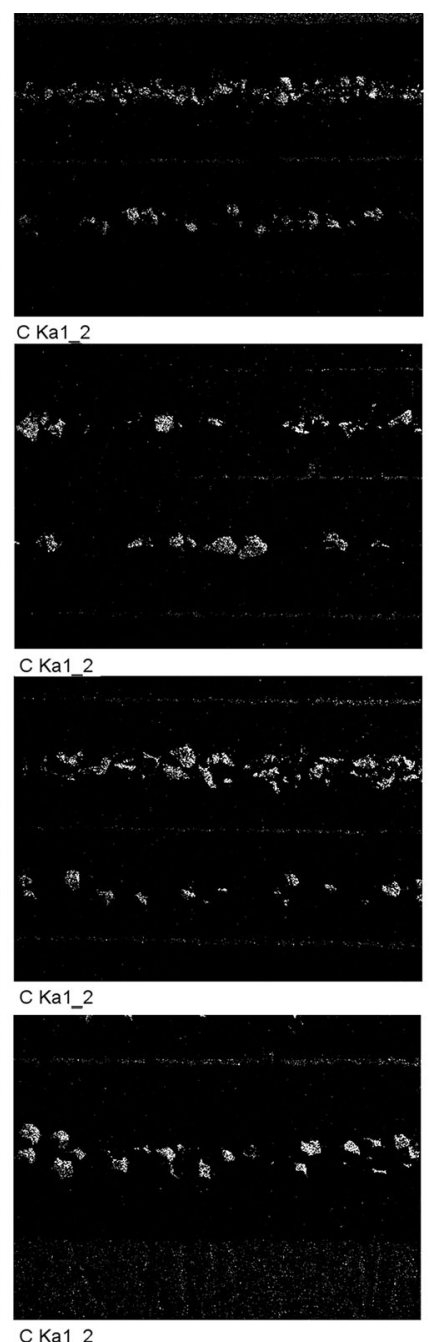
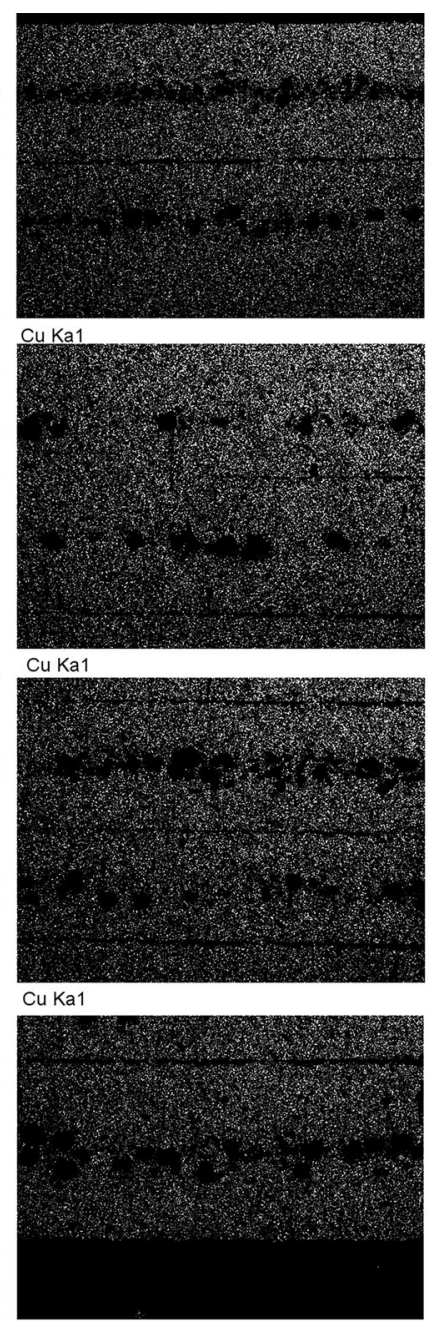

Cu Ka1
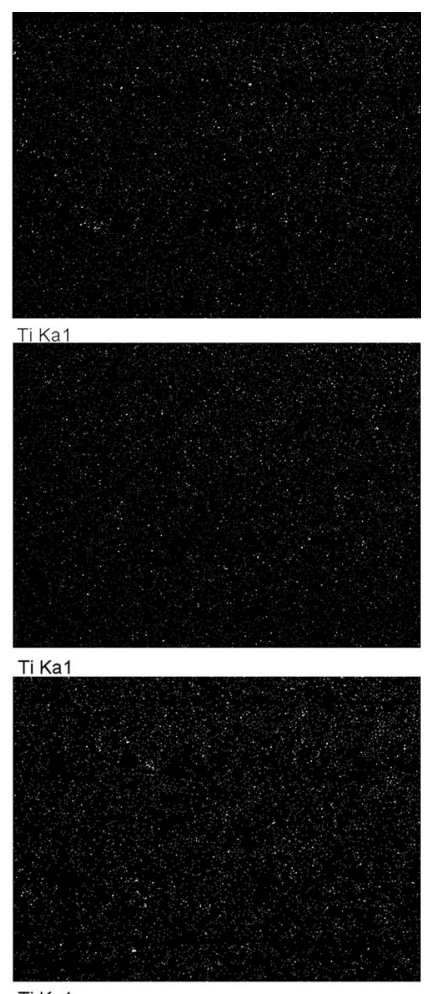

TiKa1

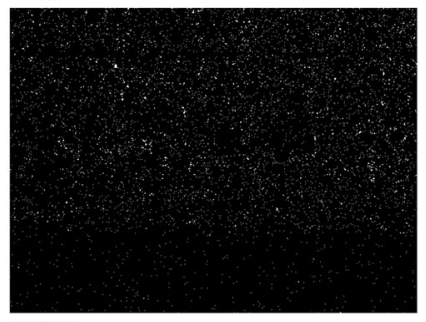

Ti Ka1

Fig. 5 SEM-EDS micrographs of the element distribution in layered composites in longitudinal section (samples from No. 1 to No. 7)

$$
K_{\text {mix }}=\frac{K_{\mathrm{m}}\left[2 K_{\mathrm{m}}+K_{\mathrm{p}}^{\text {eff }}+2\left(K_{\mathrm{p}}^{\text {eff }}-K_{\mathrm{m}}\right) V_{\mathrm{p}}\right]}{2 K_{\mathrm{m}}+K_{\mathrm{p}}^{\text {eff }}-\left(K_{\mathrm{p}}^{\text {eff }}-K_{\mathrm{m}}\right) V_{\mathrm{p}}} .
$$

The effective thermal conductivity of the reinforcement $K_{\mathrm{p}}^{\mathrm{eff}}$ is defined as:

$K_{\mathrm{p}}^{\mathrm{eff}}=\frac{K_{\mathrm{p}}}{1+2 R_{\mathrm{k}} K_{\mathrm{p}} / d}$,

where $d$ and $R_{\mathrm{k}}$ are the average diameter of the particles and the Kapitza resistance.

This model is under the assumption that the interface between the matrix and the reinforcements is perfectly sharp. If there is an interphase at the interface, additional thermal resistance caused by this interphase should be considered $[40,41]$. In order to simplify the calculation, the thin $\mathrm{TiC}$ is assumed to be the sole layer between the diamond and the copper. The interfacial thermal resistance can be expressed by:

$R_{\text {mix }}=R_{\text {diamond-TiC }}+R_{\mathrm{TiC}}+R_{\mathrm{TiC}-\mathrm{Cu}}$,

where $R_{\text {mix }}$ is the interfacial thermal resistance of the mixture layer and $R_{\mathrm{TiC}-\mathrm{Cu}}, R_{\mathrm{TiC}}$ and $R_{\mathrm{diamon}-\mathrm{TiC}}$ are the thermal resistance of $\mathrm{TiC} / \mathrm{Cu}, \mathrm{TiC}$ and diamond/TiC interface, respectively. In Eq. (7), $R_{\mathrm{TiC}}$ is calculated as follows:

$R_{\mathrm{TiC}}=l / K_{\mathrm{TiC}}$,

where $l$ and $K_{\mathrm{TiC}}$ are the thickness and the intrinsic thermal conductivity of the carbide, respectively. The $R_{\text {diamond-TiC }}$ and $R_{\mathrm{TiC}-\mathrm{Cu}}$ are described by diffuse mismatch model (DMM), which assumes that all the phonons are diffusely scattered at the interface. The Kapitza resistance based on the DMM depends solely on the phonon velocity inside the $j$ phases and on the absolute temperature, $T$, as follows: 

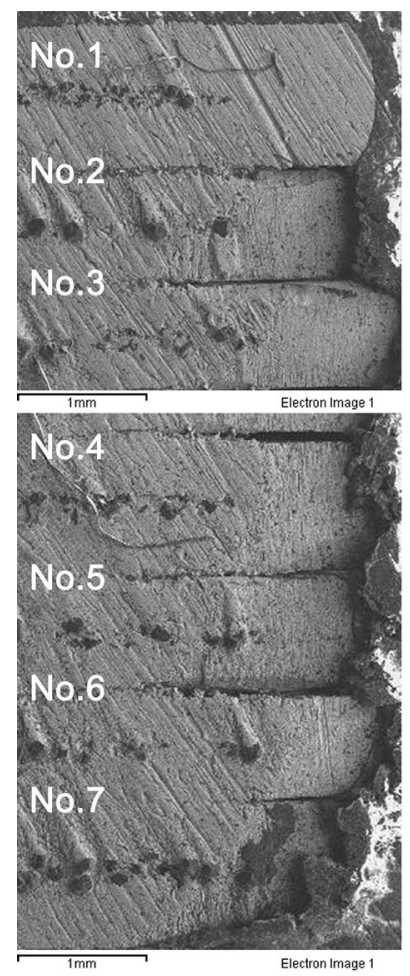

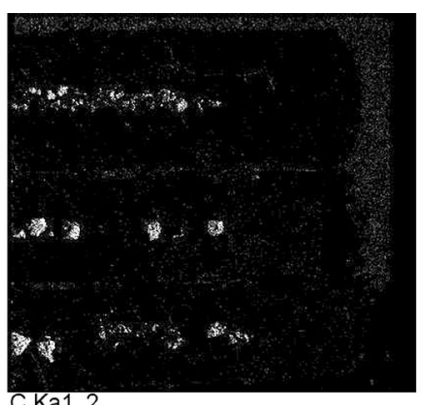

C Ka1 2

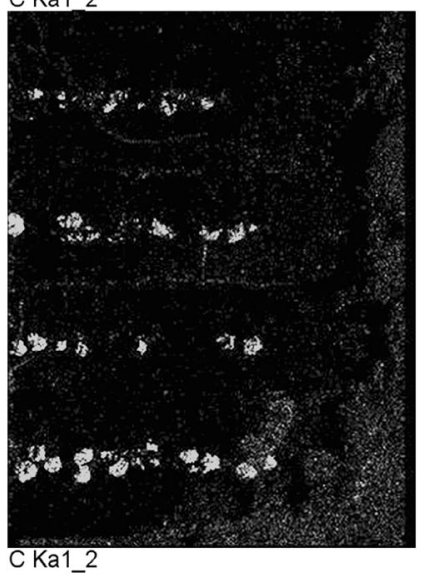

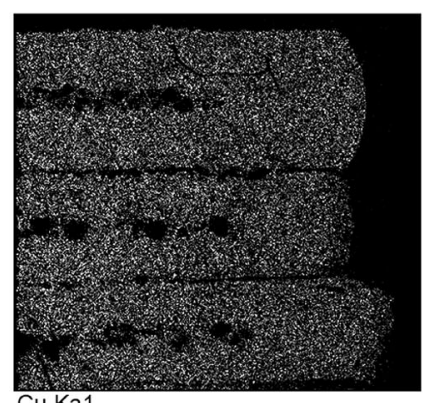

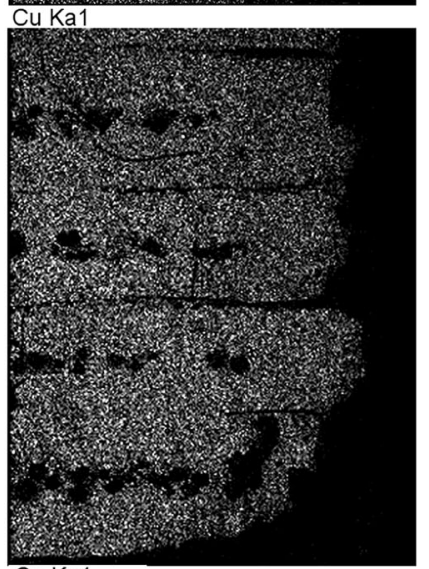

Cu Ka1
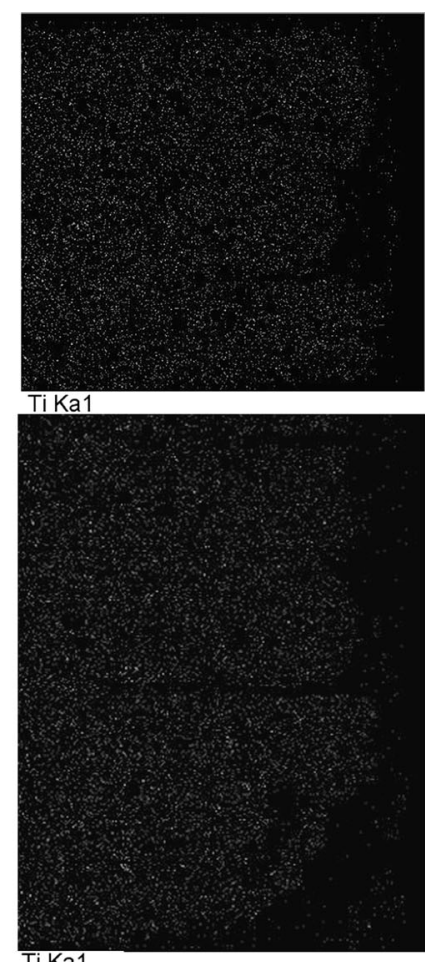

Ti Ka1

Fig. 6 SEM-EDS micrographs of the element distribution in layered composites in cross section (samples from No. 1 to No. 7)

$R_{i / 3-i}=\left[1.02 \times 10^{10} \frac{\left(\sum_{j} v_{i, j}^{-2}\right)\left(\sum_{j} v_{3-\mathrm{i}, \mathrm{j}}^{-2}\right)}{\left(\sum_{i, j} v_{i, j}^{-2}\right)}\right]^{-1} \times T^{-3}$,

where the subscripts $i$ and $3-i$ refer to the two adjacent phases on each side of the interface. The subscript $j$ represents the mode of the phonon velocity. For calculating the phonon velocity of TiC, Eq. (10) is introduced. The values of thermal conductivity $\left(K_{\mathrm{TiC}}\right)$, shear modulus $(G)$ and density $(\rho)$ of TiC are $21 \mathrm{~W} /(\mathrm{m} \mathrm{K}), 186 \mathrm{GPa}$ and $4940 \mathrm{~kg} /$ $\mathrm{m}^{3}$, respectively.

$v=(G / \rho)^{1 / 2}$.

The phonon velocity of $\mathrm{TiC}$ is $6136 \mathrm{~m} / \mathrm{s}$. In Eq. (7)-(9), the $R_{\text {diamond-TiC }}=4.98 \times 10^{-10} \mathrm{~m}^{2} \mathrm{~K} / \mathrm{W}, \quad R_{\mathrm{TiC}}=4.76 \times$ $10^{-8} \mathrm{~m}^{2} \mathrm{~K} / \mathrm{W}, \quad R_{\mathrm{TiC}-\mathrm{Cu}}=1.07 \times 10^{-10} \mathrm{~m}^{2} \mathrm{~K} / \mathrm{W} \quad$ and $R_{\text {mix }}=4.82 \times 10^{-8} \mathrm{~m}^{2} \mathrm{~K} / \mathrm{W}$. In Eq. (4)-(6), the $K_{\mathrm{p}}^{\text {eff }}=767 \mathrm{~W} /(\mathrm{m} \mathrm{K}), K_{\text {mix }}=635 \mathrm{~W} /(\mathrm{m} \mathrm{K})$, and we can obtain $K_{\mathrm{c}}=453 \mathrm{~W} /(\mathrm{m} \mathrm{K})$. From the results, the TC of the composite decreases distinctly, due to the existence of TiC. However, it is essential to the interfacial bonding. So the $R_{\mathrm{TiC}}$ should be controlled by reducing the thickness of TiC. The predicted TC shows the potential of the composite, which is expected to be used in the field of electronic packaging.

\subsection{Johnson-Cook (JC) Model of Materials}

In order to achieve a high accuracy, it is important to have an understanding of the material properties required to specify a material used in DEFORM. The properties required are dependent on the physical effects being simulated in DEFORM. For material properties, a function of material types that the user is utilizing in the simulation requires to be specified. Plastic flow data are fundamental to nearly all simulations. It governs deformation and flow behavior for any object undergoing permanent deformation. Stress required for deformation (flow stress) is generally given by a function of plastic strain, strain rate and temperature. Among the empirical and semi-empirical models, Johnson-Cook (JC) model [42-44] was successfully used for a variety of materials at different ranges of deformation temperatures and strain rates. The original JC model can be expressed as:

$$
\begin{aligned}
\sigma & =\left(A+B \varepsilon^{n}\right)\left(1+C \ln \frac{\dot{\varepsilon}}{\dot{\varepsilon_{0}}}\right)\left[1-\left(T^{*}\right)^{m}\right], \\
T^{*} & =\frac{T-T_{\text {room }}}{T_{\text {melt }}-T_{\text {room }}}
\end{aligned}
$$

where $\sigma$ is the equivalent stress; $\varepsilon$ and $\dot{\varepsilon}$ are the equivalent plastic strain and strain rate, respectively; $\dot{\varepsilon}$ is a reference strain rate taken for normalization; $A$ is the yield stress; and 
Table 2 Parameters of Johnson-Cook model

\begin{tabular}{llllllll}
\hline$A(\mathrm{MPa})$ & $B(\mathrm{MPa})$ & $C$ & $n$ & $m$ & $\begin{array}{l}T_{\text {room }} \\
\left({ }^{\circ} \mathrm{C}\right)\end{array}$ & $\begin{array}{l}T_{\text {melt }} \\
\left({ }^{\circ} \mathrm{C}\right)\end{array}$ & $k$ \\
\hline 123.7 & 435.1 & 0.022 & 0.31 & 0.83 & 20 & 1083 & 0 \\
\hline
\end{tabular}

$B$ is the strain hardening exponent, whereas $C$ is a dimensionless strain rate hardening coefficient. Parameters $n$ and $m$ are power exponents of the strain hardening and thermal softening terms. A modified JC model is used in the simulation:

$$
\begin{aligned}
& \sigma=\left(A+B \varepsilon^{n}\right)\left(1+C \ln \frac{\dot{\varepsilon}}{\dot{\varepsilon}_{0}}\right)\left(\frac{\dot{\varepsilon}}{\dot{\varepsilon}_{0}}\right)^{\alpha}\left[D-E\left(T^{*}\right)^{m}\right], \\
& D=D_{0} \exp \left[k\left(T-T_{\mathrm{b}}\right)^{\beta}\right]
\end{aligned}
$$

where $\alpha, \beta, D, D_{0}, k, E$ are model coefficients to modify the formula, considering thermal softening and strain softening. Parameters can be obtained by tensile test. Generally,
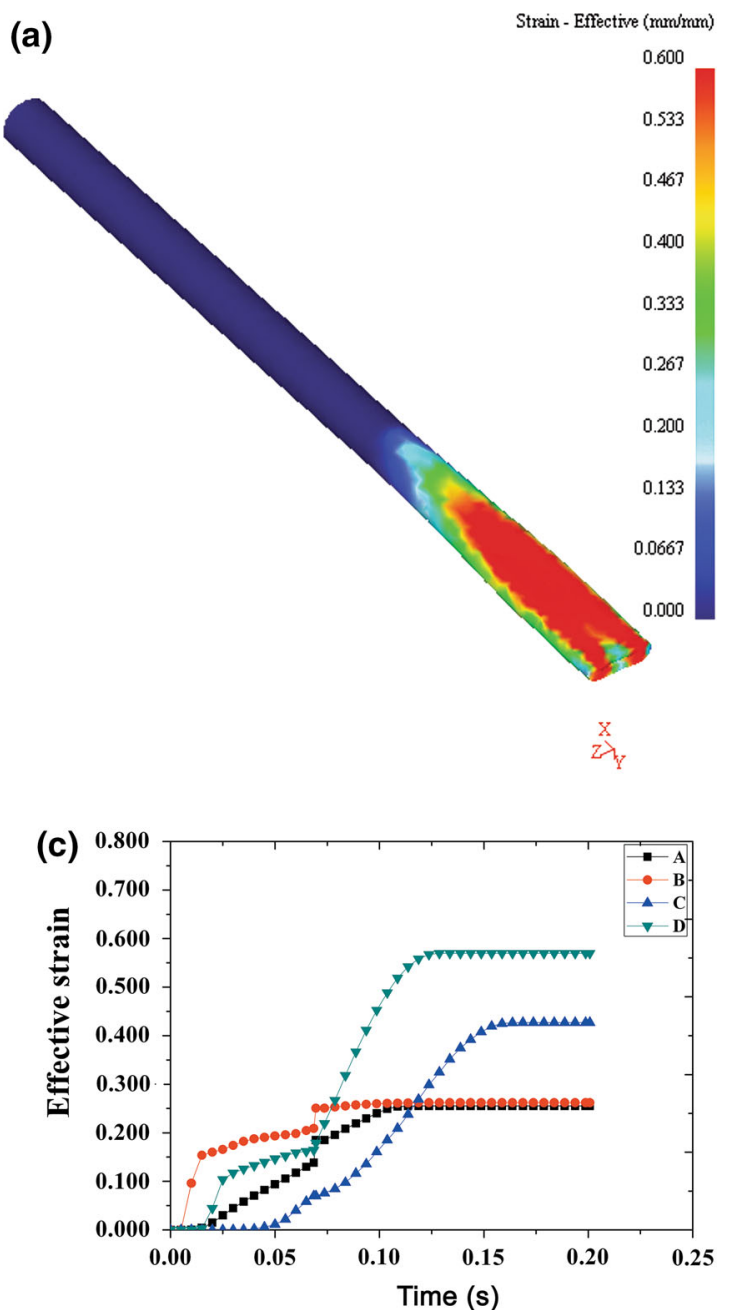

$\dot{\varepsilon}_{0}=1, D=1, D_{0}=1, \alpha=0, \beta=0$. Some parameters are listed in Table 2 from material library.

At the same time, arbitrary Lagrangian-Eulerian (ALE), which is a mature simulation method, was used. In the ALE formulation, the freedom of moving the mesh is very attractive. This could, however, be overshadowed by the burden of specific grid velocities well suited to the particular problem. As a consequence, the practical implementation of the ALE description requires that an automatic mesh displacement prescription algorithm should be provided, so it can be implemented in the model (Table 3).

\subsection{FEM Simulation Results}

\subsubsection{Broadening}

After rolling, the broadening of single $\mathrm{Cu}$ was about $1.7 \mathrm{~mm}$ and the broadening of diamond $/ \mathrm{Cu}$ was about
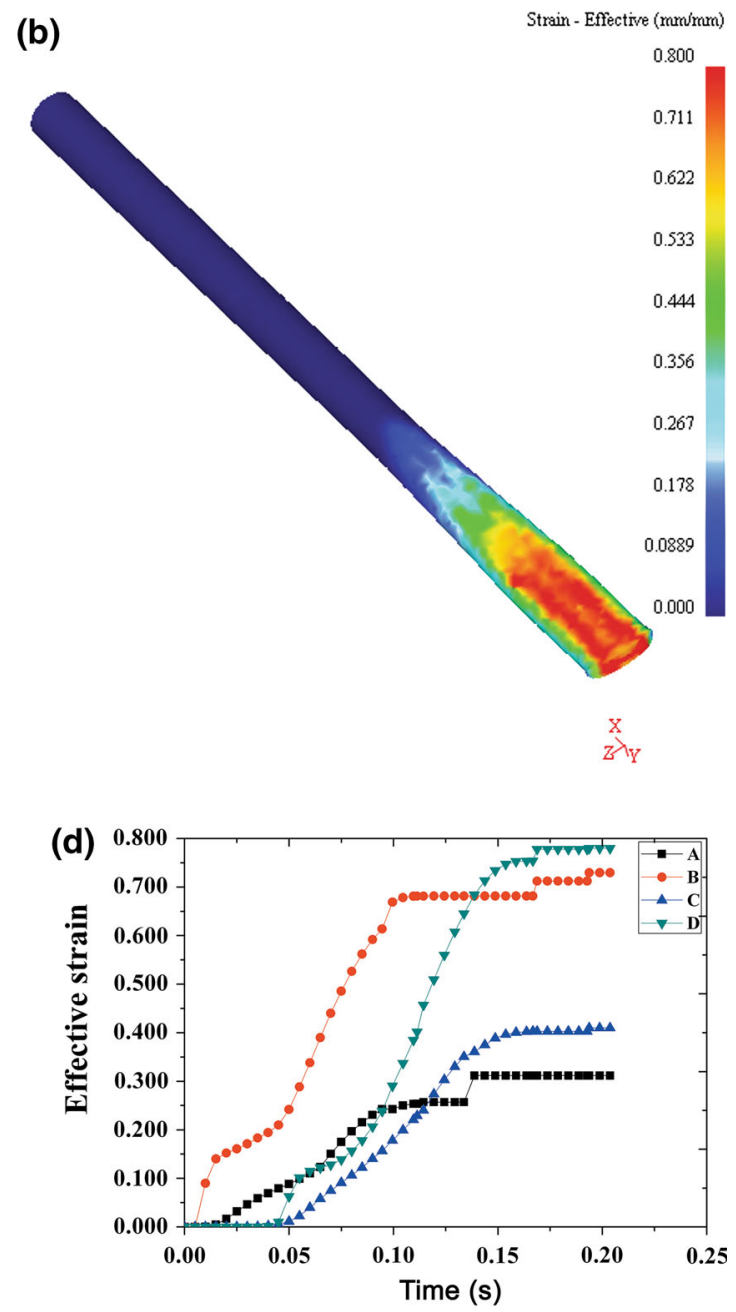

Fig. 7 Geometric distribution and plots of the effective strain under rolling: single $\mathrm{Cu} \mathbf{a}$, $\mathbf{c}$; diamond/Cu b, d 
(a)

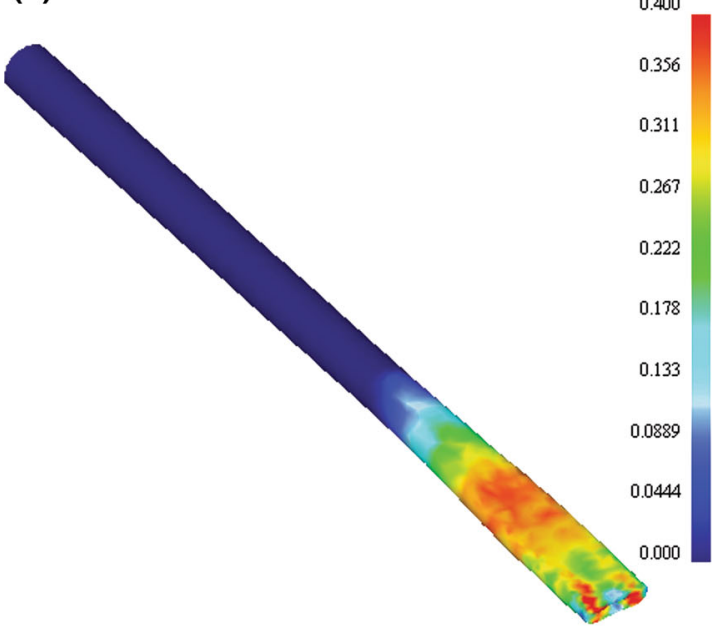

$\underset{Y \rightarrow Y}{X>1}$

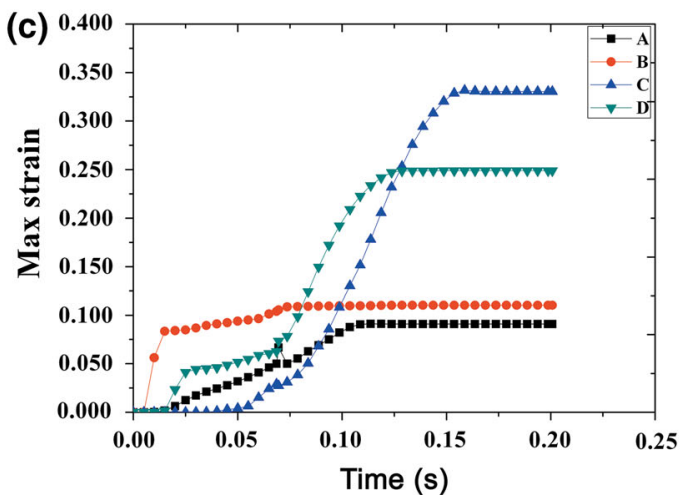

(b)

Strain - Total - Max principal (mmimm)

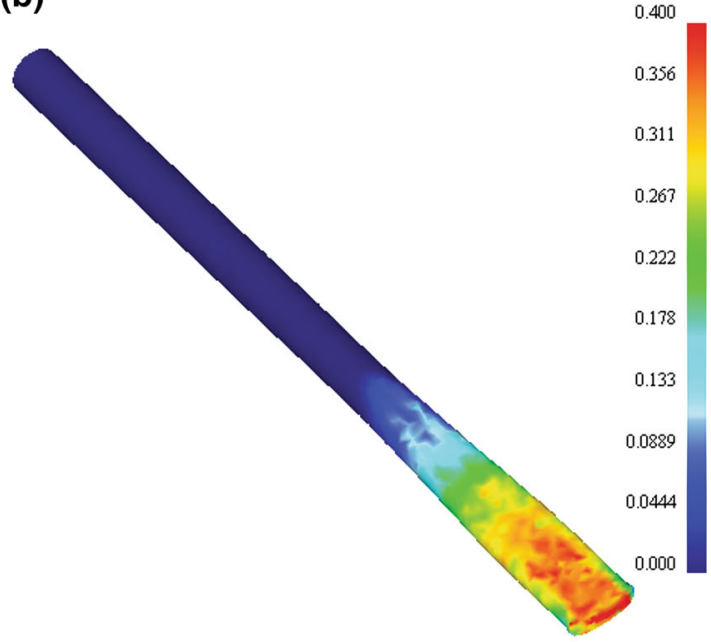

$\underset{z}{Z \lambda_{Y}}$

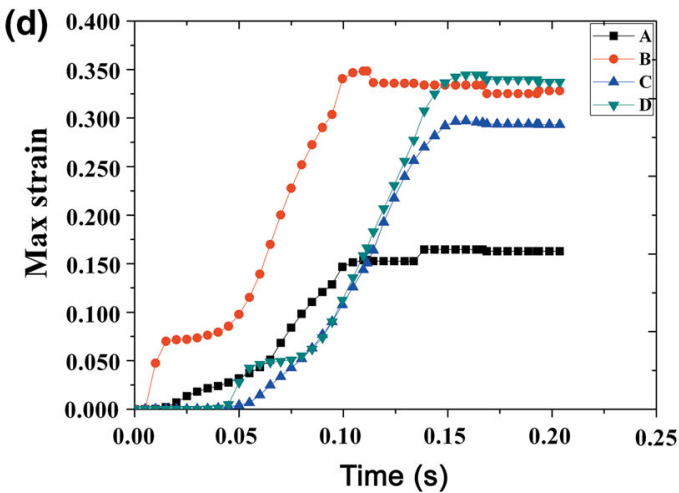

Fig. 8 Geometric distribution and plots of the maximum principal strain under rolling: single $\mathrm{Cu}$ a, $\mathbf{c} ; \operatorname{diamond} / \mathrm{Cu} \mathbf{b}, \mathbf{d}$

$1.9 \mathrm{~mm}$. The real experimental broadening was $2.0 \mathrm{~mm}$, which is close to the simulation result. The numerical results verified the reliability of the model. The copper tube was loaded with extra copper powder and diamond particles. Thus, it is obvious that the broadening of the composite is larger than that of single $\mathrm{Cu}$ under the same rolling reduction.

Table 3 Rolling broadening by the simulation

\begin{tabular}{llc}
\hline Group & Broadening $(\mathrm{mm})$ & Relative error $(\%)$ \\
\hline Single $\mathrm{Cu}$ & 1.7 & -15 \\
Diamond/Cu & 1.9 & -5 \\
Real results & 2.0 & 0 \\
\hline
\end{tabular}

\subsubsection{Effective Strain and Maximum Principal Strain}

The effective strain under rolling is shown in Fig. 7. Four points were tracked during rolling. Points $\mathrm{A}$ and $\mathrm{C}$ were along the width direction, and Points $\mathrm{B}$ and $\mathrm{D}$ were along the thickness direction. Points A and B were at the front end, and Points $\mathrm{C}$ and $\mathrm{D}$ were at the wall. During the rolling process, the effective strain increased gradually and was stable at last. For composite, Points B and D showed the higher effective strain than single $\mathrm{Cu}$. Point A showed little difference, and Point $\mathrm{C}$ showed a little drop. The deformation was intensified along the thickness direction and abated slightly along the width direction by adding diamond particles. The effective strain of diamond/Cu was about 0.7 along the thickness direction and 0.3 along the width direction. Measures should be taken to control the deformation along the thickness direction such as multi-pass rolling to prevent damage. 


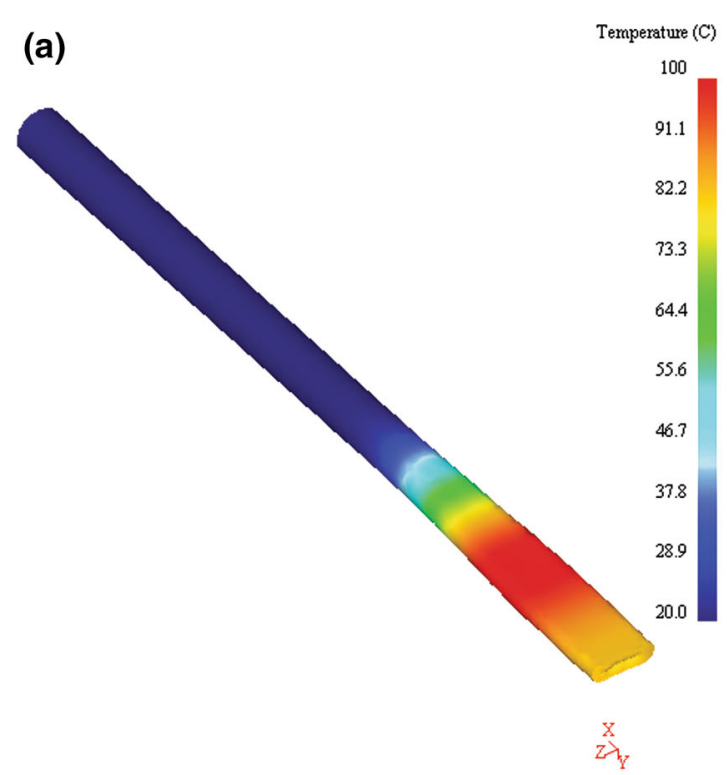

(b)

Temperature (C)

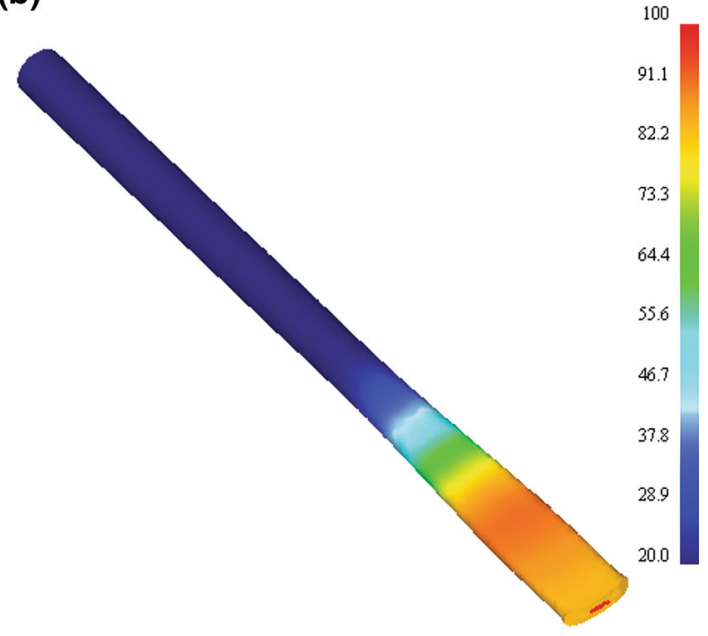

$\underset{z}{X}$

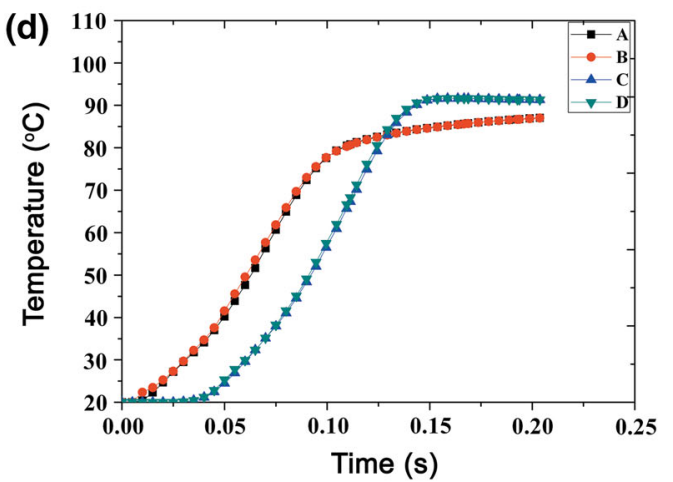

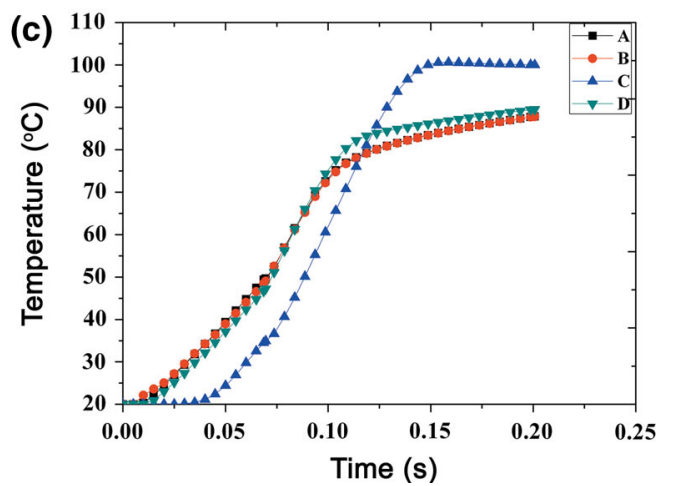

Fig. 9 Geometric distribution and plots of the temperature under rolling: single $\mathrm{Cu} \mathbf{a}, \mathbf{c}$; diamond/Cu b, d

The maximum principal strain under rolling is shown in Fig. 8. It is similar to the results of effective strain. By the strain plot and distribution graph, the area of larger strain could be predicted. Appropriate rolling reduction and multi-pass rolling could relieve the larger local strain and be conducive to forming.

\subsubsection{Temperature}

The temperature distribution under rolling is shown in Fig. 9. The maximum temperature of single $\mathrm{Cu}$ was about $100{ }^{\circ} \mathrm{C}$, and the maximum temperature of diamond/Cu was about $92{ }^{\circ} \mathrm{C}$. For the temperature change rate, diamond/Cu was slightly higher than single $\mathrm{Cu}$ by reaching $80{ }^{\circ} \mathrm{C}$ earlier. The whole temperature after rolling was lowered after introducing the diamond particles, indicating that the heat dissipation effect of the composite is better than that of single $\mathrm{Cu}$.

\section{Conclusions}

1. This paper proposed an innovative preparation method of diamond/Cu composites via the PIT process, in which a small copper tube was loaded with $\mathrm{Ti}$ - and $\mathrm{Cu}$-coated diamond particles followed by composite rolling. The composite sheet material could be obtained with unique structure of copper-clad diamond and a firm bonding between diamond particles and copper matrix.

2. In the experiment, different diamond particles were used and the analysis of contrast experiments, which involves different rolling reductions and different sizes of diamond particles, was performed. No. 7 (diamond particle size $0.12-0.15 \mathrm{~mm}$, thickness of pre-rolling $1.2 \mathrm{~mm}$ ) showed the relatively complete morphologies and homogeneous distribution.

3. For thermal performance analysis, theoretical calculation of TC was carried out. The TC of the composite 
was predicted up to $453 \mathrm{~W}(\mathrm{~m} \mathrm{~K})^{-1}$ and was of great potential in the field of electronic packaging.

4. For DEFORM-3D simulation, the area of larger strain could be predicted. By adding diamond particles, strain along the thickness direction was intensified. This study was a base for process parameter optimization and design of composite rolling process by rolling reduction control and multi-pass rolling.

Acknowledgements This study was financially supported by the National Nature Science Foundation of China (Nos. 51174028 and 51541406).

\section{References}

[1] M. Barmouz, M.K.B. Givi, J. Seyfi, Mater. Charact. 62, 108 (2011)

[2] G. Chen, W. Yang, R. Dong, M. Hussain, G. Wu, Mater. Des. 63, 109 (2014)

[3] K. Zhang, Z.Q. Shi, H.Y. Xia, K. Wang, G.W. Liu, G.J. Qiao, J.F. Yang, Ceram. Int. 42, 996 (2016)

[4] Z.Q. Tan, Z.Q. Li, G.L. Fan, X.Z. Kai, G. Ji, L.T. Zhang, D. Zhang, Compos. B Eng. 47, 173 (2013)

[5] C.Y. Chung, M.T. Lee, M.Y. Tsai, C.H. Chu, S.J. Lin, Appl. Therm. Eng. 69, 208 (2014)

[6] C. Zhang, R.C. Wang, Z.Y. Cai, C.Q. Peng, N.G. Wang, J. Mater. Sci. Mater. Electron. 26, 185 (2015)

[7] Y.B. Zhao, K.M. Liu, D.P. Lu, B. Yang, Heat Treat. Technol. Equip. 34, 31 (2013)

[8] Y.D. Kim, N.L. Oh, S.T. Oh, I.H. Moon, Mater. Lett. 51, 420 (2001)

[9] K.Q. Mu, Y.G. Kuang, Met. Funct. Mater. 9, 26 (2002)

[10] H.S. Lee, K.Y. Jeon, H.Y. Kim, S.H. Hong, J. Mater. Sci. 35, $6231(2000)$

[11] Q.L. Shang, J.M. Tao, M.C. Xu, C.J. Li, X.K. Zhu, Electron. Process. Technol. 30, 5 (2009)

[12] C. Zweben, Electron. Packag. Prod. 42, 37 (2002)

[13] S.Y. Ma, E.Z. Wang, W.Y. Lu, X. Wang, Hot Work. Technol. 37, 36 (2008)

[14] L.C. Davis, B.E. Artz, J. Appl. Phys. 77, 4954 (1995)

[15] K. Yoshida, H. Morigami, Microelectron. Reliab. 44, 303 (2004)

[16] T. Schubert, B. Trindade, T. Weißgärber, B. Kieback, Mater. Sci. Eng. A 475, 39 (2008)

[17] Y.M. Fan, H. Guo, J. Xu, K. Chu, X.X. Zhu, C.C. Jia, Int. J. Miner. Met. Mater. 18, 472 (2011)
[18] L. Weber, R. Tavangar, Scr. Mater. 57, 988 (2007)

[19] X.M. Zhang, H. Guo, F.Z. Yin, Y.M. Fan, Y.Z. Zhang, Rare Met. 30, 1034 (2011)

[20] H.B. Feng, Y. Zhou, D.C. Jia, Mater. Sci. Technol. Lond. 11, 327 (2003)

[21] W.P. Shen, W.J. Shao, Q.Y. Wang, M.L. Ma, Fusion Eng. Des. 85, 2237 (2010)

[22] A.M. Abyzov, S.V. Kidalov, F.M. Shakhov, J. Mater. Sci. 46, $1424(2011)$

[23] S.Y. Ma, E.Z. Wang, W.Y. Lu, X. Wang, Mater. Heat Treat. 36, 24 (2007)

[24] W.Z. Shao, V.V. Ivanov, L. Zhen, Y.S. Cui, Y. Wang, Mater. Lett. 58, 146 (2004)

[25] X.D. Wang, Y.H. Zhang, G.L. Xu, Alum. Fabr. 3, 22 (2008)

[26] S.H. Zhang, Y. Sun, D.M. Zhang, Q.N. Shi, J. Mater. Process. Technol. 63, 370 (1997)

[27] Q.N. Shi, S.H. Zhang, Y. Sun, D.M. Zhang, J. Mater. Process. Technol. 63, 421 (1997)

[28] Z.H. Xu, G.Y. Tang, Rare Met. Mater. Eng. 36, 296 (2007)

[29] S.J. Sun, W. Liu, X.P. Chen, Y.M. Li, J. Meng, Z.H. Han, Chin. J. Low Temp. Phys. 25, 197 (2003)

[30] K.K. Wang, S.X. Wang, K.Y. Duan, J.L. Fu, Q. Gao, Chinese Patent, No. 201410270309, 2 Aug 2014

[31] K.K. Wang, J.L. Fu, K.Y. Duan, S.X. Wang, Chinese Patent, No. 201410431568, 9 Jan 2015

[32] Y. Wang, J.Z. Zhou, Y.C. Dai, Z.Y. Xu, Forg. Stamp. Technol. 6, 81 (2005)

[33] W.D. Li, M. Wan, Y. Yan, J. Plast. Eng. 5, 156 (2014)

[34] F.Z. Yin, H. Guo, X.M. Zang, C.C. Jia, Y.M. Fan, Y.Z. Zhang, Acta Mater. Compos. Sin. 27, 138 (2010). (in Chinese)

[35] G. Fang, W.R. Gao, X.G. Zhang, Int. J. Precis. Eng. Manuf. 16, 1509 (2015)

[36] D.P.H. Hasselman, L.F. Johnson, J. Compos. Mater. 21, 508 (1987)

[37] K. Chu, C.C. Jia, X.B. Liang, H. Chen, W.J. Gao, H. Guo, Mater. Des. 30, 4311 (2009)

[38] E.T. Swartz, R.O. Pohl, Rev. Mod. Phys. 61, 605 (1989)

[39] L.W.D. Silva, M. Kaviany, Int. J. Heat Mass Tranf. 47, 2417 (2004)

[40] Y. Zhang, H. Zhang, J. Wu, X. Wang, Scr. Mater. 65, 1097 (2011)

[41] S. Ren, X.Y. Shen, C.Y. Guo, N. Liu, J.B. Zang, X.B. He, X.H. Qu, Compos. Sci. Technol. 71, 1550 (2011)

[42] G.R. Johnson, W.H. Cook, in Proceedings of the 7th International Symposium on Ballistics, the Hague, the Netherlands, 11-13 April 1983

[43] G.R. Johnson, W.H. Cook, Eng. Fract. Mech. 21, 31 (1985)

[44] I. Rohr, H. Nahme, K. Thoma, C.E. Andreson Jr., Int. J. Impact Eng. 35, 811 (2008) 